Neurosurg Focus 7 (4):Article 12, 1999

\title{
Altered diffusion and perfusion in hydrocephalic rat brain: a magnetic resonance imaging analysis
}

\author{
Eric M. Massicotte, M.D., Richard Buist, Ph.D., and Marc R. Del Bigio, M.D., Ph.D., F.R.C.P.(C) \\ Departments of Surgery (Section of Neurosurgery), Radiology, and Pathology, University of Manitoba \\ and Health Sciences Centre, Winnipeg, Manitoba, Canada
}

It can be inferred from data published in the literature that brain compression occurs in the early stages of acute hydrocephalus and that drainage of extracellular waste products is impaired. The authors hypothesized that compression of the cortical extracellular compartment will alter water distribution and retard the diffusion of fluid in the hydrocephalic brain.

Using magnetic resonance imaging proton diffusion, blood perfusion, and $\mathrm{T}_{1}$ and $\mathrm{T}_{2}$ relaxation times were determined in adult rat brain prior to, and 1 and 8 days following induction of hydrocephalus by using kaolin injection. Five anatomical regions of interest were studied. The striatum, dorsal cortex, and lateral cortex were shown to exhibit decreased $\mathrm{T}_{2}$ and apparent diffusion coefficient (ADC) values but no change in perfusion. Examination of white matter demonstrated an initial decrease in ADC followed by a significant increase. The $T_{2}$ relaxation times increased and perfusion decreased progressively from 1 to 8 days.

Acute experimental hydrocephalus causes compression of gray matter, perhaps associated with reduction in total water, which impairs diffusion of protons in the tissue. White matter compression and hypoperfusion precede the development of edema. These findings have importance for understanding the neurochemical changes that occur in hydrocephalic brains.

Key Words * hydrocephalus * magnetic resonance imaging * diffusion * blood flow * rat * extracellular fluid

Hydrocephalus is defined as an abnormal accumulation of cerebrospinal fluid (CSF) in the ventricular system. The histopathological manifestations of hydrocephalus have been documented and white matter axons in particular suffer damage.[11] The pathogenesis combines ischemia and physical forces including compression and stretching.[32] Hakim and coworkers[20] have postulated that brain compression occurs at the expense of venous blood flow and extracellular water. This is supported by observations of decreased water content in the cortices of hydrocephalic rabbits,[12] computerized tomography-determined density changes in humans with hydrocephalus,[36] and ultrastructural compression of tissue in hydrocephalic mice.[33] The accumulation of potentially toxic metabolites in 
brains of hydrocephalic rats and rabbits[14,15] leads us to hypothesize that extracellular fluid flow or molecular diffusion through the extracellular compartment is impaired following the induction of hydrocephalic compression of brain.

The diffusion of extracellular fluid is difficult to study in vivo. One approach is to analyze tracer movement by using ion-sensitive electrodes.[34] The accuracy of the technique, however, is hindered by its invasiveness. The innocuous nature of magnetic resonance (MR) imaging for the analysis of living tissues in vivo provides another approach by which apparent diffusion of water (protons) and blood perfusion can be measured noninvasively.

\section{MATERIALS AND METHODS}

\section{Animal Preparation}

All animals were treated in accordance with the guidelines set forth by the Canadian Council on Animal Care. Ten Sprague-Dawley rats weighing 200 to $250 \mathrm{~g}$ were anesthetized with ketamine/xylazine (90/10 $\mathrm{mg} / \mathrm{kg}$ intramuscularly). After shaving and flexing the neck, a 27-gauge needle was inserted into the cisterna magna, and 0.1 to $0.2 \mathrm{ml}$ of sterile kaolin suspension $(250 \mathrm{mg} / \mathrm{ml})$ was injected slowly. Magnetic resonance imaging studies were obtained prior to kaolin injection and at 1 and 8 days following induction of hydrocephalus. During this time the rats were allowed free access to food and water.

\section{Magnetic Resonance Imaging}

Proton MR imaging was performed using a Biospec/3 (Bruker, Karlsruhe, Germany) MR imager that was equipped with a $21-\mathrm{cm}$ bore magnet operating at a field of 7 tesla. The MR probe used was a 3-cm-diameter, 4.5-cm-long modified Helmholtz coil (Morris Instruments, Gloucester, ON, Canada). Rats were anesthetized with 1.5 to $2 \%$ halothane in a 70:30 mixture of $\mathrm{N}_{2} \mathrm{O}: \mathrm{O}_{2}$, and their rectal temperature was monitored and controlled using a water blanket and cooling air. Respiration was monitored via electrocardiograph electrodes placed across the chest and a respiratory monitor (Hewlett-Packard, Palo Alto, CA). All quantitative data were obtained in a single coronal brain slice located immediately anterior to the third ventricle.

\section{Measurement of $T_{2}$ Values}

To detect edema as shown by enhanced $\mathrm{T}_{2}$ values, a standard single-slice Carr-Purcell-Meiboom-Gill[25] multi-echo sequence was obtained using the following parameters: $3.5 \times 3.5 \mathrm{~cm}^{2}$ field of view, 1-mm slice thickness, 256 X 256 matrix size, TR of $1650 \mathrm{msec}$, TEs of 20, 40, 60, 80, 100, 120, 140, and 160 $\mathrm{msec}$, and four averages. The slice was positioned using a sagittal scout image obtained $1 \mathrm{~mm}$ to the right of the midline. The pituitary was used as reference point. The $\mathrm{T}_{2}$ and relative proton-density parameter image were calculated by fitting the multiecho image series point-by-point to a simple exponential decay.

\section{Diffusion-Weighted Imaging}

Quantitative diffusion maps were measured using magnetization-prepared TurboFLASH as modified by Thomas, et al.[40] It consists of a driven-equilibrium Fourier transform sequence during which a pair of 2-msec diffusion-sensitizing gradients separated by $20 \mathrm{msec}$ is applied, followed by a TurboFLASH imaging sequence (TE $2.3 \mathrm{msec}$, TR $3.7 \mathrm{msec}$ ). Linear phase encoding was used with the central line of $\mathrm{k}$-space shifted to the 25 th phase-encoding step to minimize $\mathrm{T}_{1}$ recovery during the imaging sequence. 
For each image 48 averages were accumulated. To quantify the apparent diffusion coefficient (ADC) of water, a series of images was produced with varying degrees of diffusion weighting (expressed as a beta value) by increasing the strength of the diffusion gradient. For each beta value, two images need to be acquired, differing by a $90^{\circ}$ phase shift in the second $90^{\circ}$ radio frequency (RF) pulse of the driven-equilibrium Fourier transform preparation and the imaging pulses. When these two images are combined, one obtains images that are free of eddy current artifacts. The combination algebra consists of a pixel-by-pixel calculation of the square root of the sum of the square of the individual image intensity. Images with eight different beta values of $21,84,189,336,525,756,1029$, and 1344 seconds $/ \mathrm{mm}^{2}$ were obtained, and ADC values were calculated from the decay constant obtained by pixel-by-pixel fitting of the image series to a simple exponential decay. A field of view of $5 \times 5 \mathrm{~cm}^{2}$, slice thickness of $2 \mathrm{~mm}$, and a matrix size of $128 \times 128$ were used at a slice position identical to that for the $\mathrm{T}_{2}$-weighted images.

\section{Perfusion-Weighted Imaging}

Quantitative perfusion maps were measured using the arterial spin-tagging method[31] as preparation for TurboFLASH readout images. An RF field of 100 milliGauss was used in the presence of a 2-Gauss $/ \mathrm{cm}$ gradient with a RF offset chosen so that the labeling plane was located perpendicular to the long axis of the brain at a distance of $7 \mathrm{~mm}$ from the posterior edge of the cerebellum. The resulting offset was $17,000 \mathrm{~Hz}$. The labeling time was chosen to be 2 seconds as a compromise between labeling efficiency and time efficiency. The post-spin tagging delay, which minimizes intravascular artifacts and sensitivity to variable transit time, was set to be $400 \mathrm{msec}$.[1] This time was calculated from the end of the spin-tagging time to the central line of the k-space. The TurboFLASH parameters were identical to the aforementioned parameters for the diffusion imaging, except that the central line of $\mathrm{k}$-space was placed halfway through the imaging sequence. A four-step protocol was used to control for the magnetization transfer effect.[35] The brain-blood partition coefficient, $f$, was assumed to be 0.9 throughout the brain. The spin-tagging efficiency, alpha, was assumed to be 0.75 for all rats. The $\mathrm{T}_{1}$ relaxation was measured in a separate experiment (described above). The two perfusion-weighted images were summed and the sum was subtracted from the sum of the two control images. The resulting images were weighted only by the cerebral blood flow.

\section{Imaging of $T_{1}$ Values}

Maps of $\mathrm{T}_{1}$ values in the presence of flow were acquired using an inversion recovery-prepared TurboFLASH imaging technique.[5] An adiabatic hyperbolic secant the slice-selective pulse with the slice position centered on the imaging slice and slice thickness of $5 \mathrm{~mm}$ was used as inversion pulse. The TurboFLASH readout image was then acquired following a series of effective inversion times of 60, 311, $621,1001,1490,2179,3358$, and $8550 \mathrm{msec}$. Effective inversion time was calculated as the time elapsed between the inversion pulse and the central line of the k-space. All parameters for the imaging sequence were identical to those used for the diffusion imaging, except that six averages were used. Because the signal-to-noise ratio was too low to allow pixel-by-pixel $T_{1}$ value calculations, an average $T_{1}$ for a given region of interest (ROI) was calculated using a three-parameter fit to the average image intensities of the inversion-recovery series.

\section{Absolute Perfusion Calculations}

Because $\mathrm{T}_{1}$ values could not be calculated on an individual pixel basis, the average absolute perfusion rate was calculated using the following equation:[31] 


$$
\begin{aligned}
& f=h\left(\frac{1}{\mathrm{~T}_{0}}+\delta\right)\left(\frac{\mathrm{M}_{\mathrm{b}}^{\mathrm{con}}-\mathrm{M}_{\mathrm{b}}^{\mathrm{im}}}{2 \alpha \mathrm{M}_{\mathrm{b}}^{\operatorname{con}}}\right) \\
& \text { where } \delta=\frac{\mathrm{k}_{\mathrm{i} \alpha}}{1+\mathrm{k}_{\mathrm{rev}} \mathrm{T}_{\mathrm{m}}+\mathrm{R}_{\mathrm{m}} \mathrm{T} 1_{\mathrm{II}}},
\end{aligned}
$$

$T_{0}$ is the measured $T_{1}$ value in the presence of flow; $M_{b}$ con is the intensity of the control images; $M_{b}{ }^{\text {inv }}$ is the intensity of the images acquired after arterial inversion; $\mathrm{k}_{\mathrm{for}} \mathrm{k}_{\mathrm{rev}}$ are the forward and reverse rate constants for the magnetization transfer process; $T 1_{m}$ is the $T_{1}$ value of the macromolecules; and $R_{m}$ is the saturation rate of the macromolecular spins. In practice, because delta is less than $10 \%$ of $1 / \mathrm{T}_{1}$ and is not expected to vary itself by more than $10 \%$, we used a constant value of $0.039 \mathrm{~s}^{-1}$. For technical reasons absolute perfusion could not be calculated for one animal at 8 days.

\section{Analysis of MR Images}

The ROI from five anatomical regions were selected. Ventricles, white matter, striatum, and dorsal and lateral cortex were traced bilaterally on the proton-density images, which displayed the greatest white-gray matter contrast. These ROI were then applied to all other corresponding images to compare equivalent regions for each rat at each time point. An example of the ROI tracing is shown in Fig. 1.

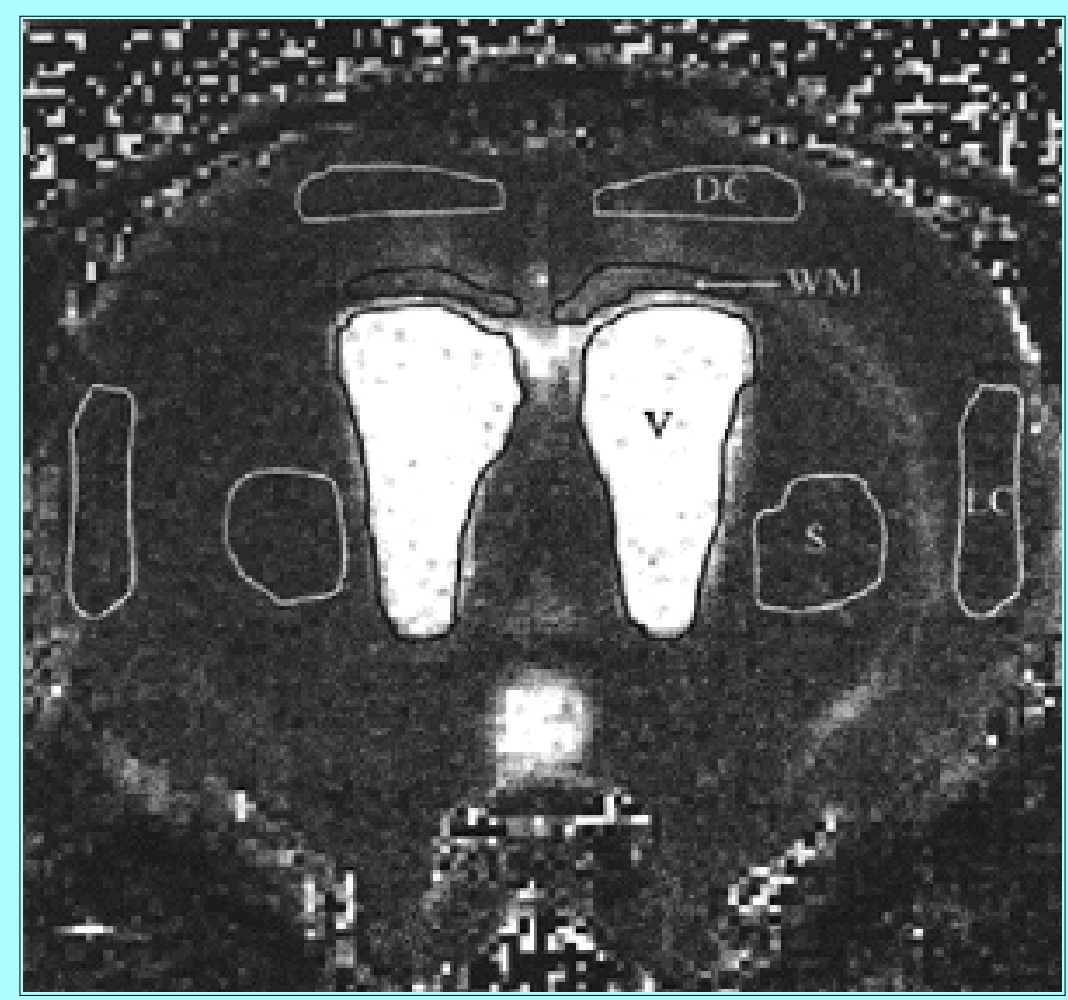

Fig. 1. Proton MR image of coronal slice obtained 8 days after induction of hydrocephalus in a rat brain, showing an example of the ROIs selected for determination of MR parameters in ventricle (V), dorsal cortex (DC), lateral cortex (LC), striatum (S), and white matter (WM). 
Data are presented as the mean \pm standard error of the mean. Statistical analysis consisted of analysis of variance with post-hoc Bonferroni-Dunn calculations for intergroup comparisons. Statistical significance is defined as $\mathrm{p}<0.05$.

\section{RESULTS}

The rats generally tolerated the kaolin injections well. There was one death among the 10 rats used. The lateral ventricle size was measured on a single coronal slice anterior to the third ventricle. Mean ventricle area for control rats was $0.0096 \pm 0.001 \mathrm{~cm}^{2}$. It increased significantly to $0.034 \pm 0.004 \mathrm{~cm}^{2}$ at 1 day and to $0.072 \pm 0.005 \mathrm{~cm}^{2} 8$ days after injection of kaolin.

Quantitative values for blood perfusion, $\mathrm{ADC}$ in $\mathrm{X}$ (left-right) and $\mathrm{Y}$ (dorsoventral) orientation, and $\mathrm{T}_{1}$ and $\mathrm{T}_{2}$ relaxation times were obtained for dorsal and lateral cerebral cortex, periventricular white matter, and striatum (Fig. 1).

Results of tests in the cerebral cortex are shown in Table 1. In control rat brain, diffusion was less restricted (that is, the ADC value was greater) in the direction parallel to the radially oriented dendrites. The ADC values were greater for lateral cortex compared with dorsal cortex in the X orientation, and the reverse was noted in the $\mathrm{Y}$ orientation. The ADC value in the $\mathrm{X}$ orientation did not change significantly in either the dorsal or lateral cortex following development of ventriculomegaly. The ADC in the Y orientation decreased significantly in both the dorsal and lateral cortex with the onset of hydrocephalus. The $T_{2}$ values declined progressively as ventriculomegaly increased. The $T_{1}$ value was transiently decreased at 1 day. Perfusion did not change in either location. 
RESULTS OF MR IMAGNG ANALYSS OF DORSAL CORTEX, LATERAL CORTEX, STRMTUM, AND WHTE MATTER PRIOR TO AND FOLLOWING INDUCTON OF HVDROCEPHALUS

\begin{tabular}{|c|c|c|c|c|c|c|}
\hline \multirow{2}{*}{\multicolumn{2}{|c|}{$\begin{array}{l}\text { Aratomical } \\
\text { Site, Time }\end{array}$}} & \multicolumn{2}{|c|}{ Diffusion $\left(\mu m^{2} / s e x\right)$} & \multirow[b]{2}{*}{$\begin{array}{l}T_{1} \text { val ue } \\
\text { (msec) }\end{array}$} & \multirow[b]{2}{*}{$\begin{array}{l}\mathrm{T}_{2} \text { val ue } \\
\text { [msex] }\end{array}$} & \multirow{2}{*}{$\begin{array}{c}\text { Perfusion } \\
\text { (ml thoodl100 g } \\
\text { tissudmin) }\end{array}$} \\
\hline & & $\stackrel{x}{\text { Orientation }}$ & $\stackrel{Y}{\text { Oriertation }}$ & & & \\
\hline \multicolumn{7}{|c|}{ dorsal cortex } \\
\hline & ontrol & $729.1 \pm 25.6$ & $1114.1 \pm 41.5$ & $1849.2 \pm 23.8$ & $71.1 \pm 0.8$ & $219.7 \pm 9.3$ \\
\hline & $\begin{array}{l}\text { day } \\
\text { dais }\end{array}$ & $\begin{array}{l}709.6 \pm 23.8 \\
753.0 \pm 22.6\end{array}$ & $\begin{array}{l}945.5 \pm 31.2 \dagger \\
954.9 \pm 20.1 \dagger\end{array}$ & $\begin{array}{l}1787.0 \pm 10.7 \\
1878.4 \pm 30.5 \ddagger\end{array}$ & $\begin{array}{l}67.9 \pm 1.2 \mathrm{\S} \\
66.2 \pm 0.5 \S\end{array}$ & $\begin{array}{l}249.1 \pm 10.5 \\
208.8 \pm 14.1\end{array}$ \\
\hline \multicolumn{7}{|c|}{ lateral cortex } \\
\hline & ontrol & $824.2 \pm 28.2$ & $954.6 \pm 46.7$ & $1880.0 \pm 20.9$ & $68.8 \pm 0.9$ & $245.9 \pm 12.8$ \\
\hline & $\begin{array}{l}\text { day } \\
\text { days }\end{array}$ & $\begin{array}{l}839.7 \pm 26.8 \\
830.2 \pm 22.0\end{array}$ & $\begin{array}{l}788.8 \pm 28.3^{x \times} \\
843.8 \pm 25.5^{x x}\end{array}$ & $\begin{array}{l}1785.4 \pm 20.9 \dagger \dagger \\
1834.0 \pm 19.8\end{array}$ & $\begin{array}{l}66.8 \pm 1.4 \\
62.5 \pm 0.6 \ddagger \ddagger\end{array}$ & $\begin{array}{l}281.8 \pm 12.3 \\
238.5 \pm 16.1\end{array}$ \\
\hline \multicolumn{7}{|c|}{ striatum } \\
\hline & ontrol & $673.7 \pm 21.9$ & $999.1 \pm 43.0$ & $1749.7 \pm 19.4$ & $70.7 \pm 1.2$ & $213.4 \pm 8.6$ \\
\hline & day & $643.6 \pm 18.7$ & $849.8 \pm 31.088$ & $1734.9 \pm 13.6$ & $67.7 \pm 1.4$ & $207.2 \pm 5.3$ \\
\hline \multicolumn{7}{|c|}{ 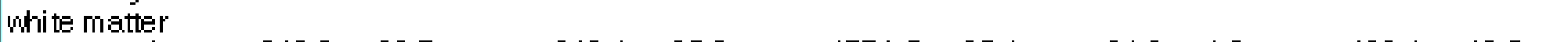 } \\
\hline & ontrol & $919.3 \pm 33.7$ & $840.1 \pm 35.8$ & $1771.5 \pm 25.4$ & $61.9 \pm 1.2$ & $169.1 \pm 13.5$ \\
\hline & $\begin{array}{l}\text { day } \\
\text { days }\end{array}$ & $\begin{array}{c}834.0 \pm 25.9 \\
1171.5 \pm 108.6 \mathrm{tt \dagger}\end{array}$ & $\begin{array}{r}735.6 \pm 33.5 \\
1027.2 \pm 83.3 \mathrm{tt} t\end{array}$ & $\begin{array}{l}1794.1 \pm 53.4 \\
1851.4 \pm 103.4\end{array}$ & $\begin{array}{l}63.6 \pm 1.5 \\
78.2 \pm 5.8 \ddagger \ddagger\end{array}$ & $\begin{array}{c}105.8 \pm 5.6 \ddagger \ddagger \ddagger \\
93.0 \pm 12.5 \ddagger \ddagger \ddagger\end{array}$ \\
\hline \multirow{2}{*}{\multicolumn{7}{|c|}{$\approx \quad$ Values are represented as the mean \pm standard }} \\
\hline \multirow{2}{*}{\multicolumn{3}{|c|}{$\begin{array}{l}\dagger \quad \text { Significant difference from control }(p<0.002) \text {. } \\
\pm \quad \text { Sanificant difference from } 1 \text { dav }(0<0.02) \text {. }\end{array}$}} & & & & \\
\hline & Sgnific & difference from $1 \mathrm{de}$ & $(\mathrm{p}<0.02)$ & & & \\
\hline \multicolumn{7}{|c|}{ S Ggnificant difference from control $(p<0.015)$. } \\
\hline \multicolumn{7}{|c|}{ Sgnificant difference from control $(p<0.03)$. } \\
\hline \multirow{3}{*}{ 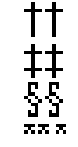 } & Sgnific & difference from cont & ol $(p<0.007)$ & & & \\
\hline & Signific & difference from cont & ol and 1 day $(p<$ & & & \\
\hline & $\mathrm{s}$ & difference from cor & $(p<0.001)$ & & & \\
\hline \multirow{2}{*}{$\begin{array}{l}\dagger \dagger \\
+\ddagger\end{array}$} & Sgnific & $\begin{array}{l}\text { difference from cont } \\
\text { difference from cont }\end{array}$ & ol and 1 day $(p<x$ & & & \\
\hline & & 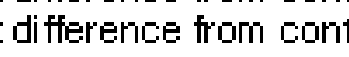 & ol $(p<0.0004)$ & & & \\
\hline
\end{tabular}

Results of MR evaluation of the striatum are presented in Table 1. In control rats, as in cortex, there was considerable ADC anisotropy with more liberal diffusion along the $\mathrm{Y}$ orientation. After induction of hydrocephalus, the ADC values decreased in both orientations by 8 days postinduction, and $\mathrm{T}_{2}$ values declined gradually. Perfusion did not change.

The results of MR evaluation of the white matter are presented in Table 1. In the control state, mild ADC anisotropy was detected, with a slight diffusion preference in the X orientation. The ADC values in $X$ and $\mathrm{Y}$ orientations were decreased at 1 day after induction of hydrocephalus and showed a significant increase at 8 days postinduction. The $\mathrm{T}_{2}$ relaxation time was increased at 8 days. The $\mathrm{T}_{2}$-weighted $\mathrm{MR}$ images demonstrated the development of edema in white matter at 8 days only (data not shown). Perfusion was significantly decreased by $38 \%$ and $45 \%$ at 1 and 8 days postinjection, respectively.

The data were further analyzed to determine interrelationships between the various parameters. The results of regression analysis showed that ventricle size positively influenced $T_{1}$ and $T_{2}$ values in white matter at 8 days $\left(\mathrm{r}^{2}=0.52\right.$ and 0.51 , respectively). Perfusion in white matter was negatively influenced by ventricle size on Day $1\left(\mathrm{r}^{2}=0.11\right)$. Ventricle size also influenced $\mathrm{T}_{1}$ and $\mathrm{T}_{2}$ values positively in dorsal and lateral cortex on Day $1\left(\mathrm{r}^{2}=0.52\right.$ and 0.66$)$. The white matter of hydrocephalic rats at 8 days was shown to exhibit a negative correlation between perfusion and $\mathrm{T}_{1}(\mathrm{r}=-0.49)$ and $\mathrm{T}_{2}(\mathrm{r}=-0.40)$. The $\mathrm{T}_{1}$ 
and $\mathrm{T}_{2}$ values correlated well in white matter (control, $r=0.50 ; 1$ day, $r=0.90$; eight days $r=0.93$ ) but not in other anatomical locations. There were no consistent correlations between ADC X orientation, ADC $\mathrm{Y}$ orientation, $\mathrm{T}_{2}$ values, and $\mathrm{T}_{1}$ values in any location at any time point.

\section{DISCUSSION}

In control rat brain the presence of ADC anisotropy in the dorsal and lateral cortex seems to be related to orientation of major dendrites.[23] Our control $\mathrm{T}_{2}$ values are somewhat higher than those reported by others, perhaps because of differences in technique, but the relative differences between values obtained in gray and white matter are similar.[8] These discrepancies may be a result of the precise MR method used. Persistently decreased $\mathrm{T}_{2}$ and transiently decreased $\mathrm{T}_{1}$ relaxation times in both cortical locations of hydrocephalic rats suggest that water content may be diminished in these locations.[4,18,28,42] This concurs with an earlier experiment conducted in hydrocephalic rabbits in which water content was measured by specific gravity.[12] In hydrocephalic rats, the compression caused by enlarging the ventricles is centrifugal, with perhaps a greater effect exerted on dorsal cortex than that on lateral cortex. However, for reasons that are not obvious the ADC values decreased in both areas equally by 15 to $17 \%$ in the Y orientation only. The ADC values are correlated with increases in the extracellular water fraction, indicating that protons can diffuse more freely when the extracellular space is larger;[30] the reverse should also be true. Significantly decreased ADC and $\mathrm{T}_{2}$ values have been observed in cortical gray matter of rats with serum hyperosmolarity associated with untreated diabetes.[21] Those changes were considered to be caused by dehydration of brain tissue. Overall our data suggest that cortical water content might be decreased and that diffusion of water through cortex is impaired in the initial stages of experimental hydrocephalus. Compression of the extracellular compartment, as predicted by mathematical models of hydrocephalus,[27] would explain the impairment of water diffusion and the loss of water. In five adult patients with chronic hydrocephalus of unknown duration, however, no any changes in gray matter ADC were exhibited.[19] In infant rodents with congenital hydrocephalus the cortex is severely distorted and may itself become edematous in later stages.[26,33] A similar increase in cortical water has been observed in hydrocephalic rabbits.[39] Clearly the timing of this type of experiment and the tempo of ventricular enlargement can influence the findings.

Striatal gray matter is composed of a complex network of cells and cell processes, the orientations of which are random or isotropic. The pronounced ADC anisotropy in the normal state, with greater ADC values in the $\mathrm{Y}$ orientation, is likely a consequence of the white matter bundles that run predominantly in a vertical direction.[29] As in the cerebral cortex, hydrocephalus was associated with decreased ADC and $\mathrm{T}_{2}$ values, presumably for the same aforementioned reasons.

Braun and coworkers[6] determined ADC values in hydrocephalic adult rat brains by using a 4.7-tesla MR system in the Z (front-to-back) orientation only. Their control rats had ADC values of 760 $\mu \mathrm{m}^{2} /$ second in the striatum and $700 \mu \mathrm{m}^{2} /$ second in the cortex, which are similar to our determinations. Following induction of hydrocephalus with kaolin they observed no significant changes from 1 to 8 weeks.[6] The difference between their results and ours could be accounted for by the diffusion orientation, the strength of the magnetic field, or the severity of hydrocephalus; the rats treated in our study did not survive more than 2 weeks, indicating that the CSF disturbances are more severe.

In control white matter, $\mathrm{ADC}$ in the $\mathrm{X}$ orientation is greater than in the $\mathrm{Y}$ orientation. This anisotropy is due to the arrangement of parallel crossing axons.[23,43] After induction of hydrocephalus, the initial 
decrease in the ADC values suggests that white matter, like gray matter, is compressed during the earliest stages of ventricular enlargement. This should not be surprising because the white matter is nearest to the enlarging ventricle. We suggest that there is no prior documentation of this phenomenon because other investigators have not examined the process early enough using appropriate methods. Subsequent bidirectional increase in ADC values could be explained by an increase in extracellular free water.[30,39] Qualitative increases in white matter ADC values have been previously reported in hydrocephalic rats $[6,7,17]$ and in humans with chronic hydrocephalus.[19] An increase in tissue water is supported by the $\mathrm{T}_{2}$ increase at 8 days. $[2,3,42]$ Although both $\mathrm{T}_{1}$ and $\mathrm{T}_{2}$ values correlate with water content in normal tissues, $[18,28]$ we did not detect any change in white matter $T_{1}$. Hypoperfusion has been demonstrated in the white matter of hydrocephalic animal brains by using other methods.[7,9,10,22] The compression and traction exerted by the enlarging ventricles on capillaries[13] could explain the decrease in perfusion. Analysis of our data suggests that, in this model of hydrocephalus, white matter edema only becomes significant after a period of reduced blood perfusion and tissue compression. White matter is most susceptible to ventriculomegaly because of its proximity to the ventricles and, perhaps, its relative lack of structural integrity.[11] We postulate that hypoperfusion triggers the development of edema through cytological injury to axons and glia[16] or by disruption of the blood-brain barrier.[32] Note that this does not exclude the more conventional view that periventricular edema in hydrocephalus is due to "transependymal" movement of CSF.[24,37] Despite compression of gray matter in hydrocephalus, this tissue is resistant to hypoperfusion. Greater structural integrity or denser capillary network may offer some degree of protection.

Although the results presented here support our hypothesis that hydrocephalus causes extracellular space compression at least in gray matter, caution should be exercised. Limitations of this study include the small number of animals used and potential inaccuracies in selection of ROI, especially in white matter. The measured values for blood perfusion are greater than those normally reported. A possible explanation is that the rats hypoventilated during spontaneous breathing after induction of anesthesia. Mild elevation of $\mathrm{PCO}_{2}$ can increase brain perfusion dramatically.[41] The important point in this experiment is the relative and significant change in white matter perfusion. Unlike the more invasive microelectrode methods that measure tracer molecule diffusion through the extracellular compartment,[34] MR imaging measures only the ADC of water that is indirectly related to the quantity of "free" or unbound water. Distinction between intracellular and extracellular water cannot be made. Considering the brief times during which the MR measurements are made, it is unlikely that the ADC is influenced by fluid bulk flow that occurs along larger perivascular channels.[38]

\section{CONCLUSIONS}

The MR imaging methods used in this experiment allow repeated in vivo analyses of rat brain prior to and during the development of hydrocephalus. Decreased diffusion and $\mathrm{T}_{2}$ values in the cortex suggest that the tissue is compressed and that water is squeezed out. Assuming that this water is removed from the extracellular compartment, this could compromise diffusion of extracellular molecules, [34] hence explaining the accumulation of waste products.[15] The relative hypoperfusion of the white matter may contribute to the development of edema. Confirmation of these results in humans could provide further information on this complex disorder, especially with regard to understanding of the neurochemical dysfunction.

\section{Acknowledgment}


We thank Cathy Crook for excellent technical assistance.

\section{References}

1. Alsop DC, Detre JA: Reduced transit-time sensitivity in noninvasive magnetic resonance imaging of human cerebral blood flow. J Cereb Blood Flow Metab 16:1236-1249, 1996

2. Andersen C: In vivo estimation of water content in cerebral white matter of brain tumour patients and normal individuals: towards a quantitative brain oedema definition. Acta Neurochir 139:249-256, 1997

3. Baratti C, Barnett AS, Pierpaoli C: Comparative MR imaging study of brain maturation in kittens with T1, T2, and the trace of the diffusion tensor. Radiology 210:133-142, 1999

4. Barnes D, McDonald WI, Johnson G, et al: Quantitative nuclear magnetic resonance imaging: characterization of experimental cerebral oedema. J Neurol Neurosurg Psychiatry 50:125-133, 1987

5. Bluml S, Schad LR, Stepanow B, et al: Spin-lattice relaxation time measurement by means of a TurboFLASH technique. Magn Reson Med 30:289-295, 1993

6. Braun KPJ, de Graaf RA, Vandertop WP, et al: In vivo 1H MR spectroscopic imaging and diffusion weighted MRI in experimental hydrocephalus. Magn Reson Med 40:832-839, 1998

7. Braun KPJ, Dijkhuizen RM, de Graaf RA, et al: Cerebral ischemia and white matter edema in experimental hydrocephalus: a combined in vivo MRI and MRS study. Brain Res 757:295-298, 1997

8. Cremillieux Y, Ding S, Dunn JF: High-resolution in vivo measurements of transverse relaxation times in rats at 7 Tesla. Magn Reson Med 39:285-290, 1998

9. da Silva MC, Drake JM, Lemaire C: Changes in 31P spectroscopy in neonatal hydrocephalus. Childs Nerv Syst 9:44, 1993 (Abstract)

10. da Silva MC, Michowicz S, Drake JM, et al: Reduced local cerebral blood flow in periventricular white matter in experimental neonatal hydrocephalus--restoration with CSF shunting. J Cereb Blood Flow Metab 15:1057-1065, 1995

11. Del Bigio MR: Neuropathological changes caused by hydrocephalus. Acta Neuropathol 85:573-585, 1993

12. Del Bigio MR, Bruni JE: Cerebral water content in silicone oil-induced hydrocephalic rabbits. Pediatr Neurosci 13:72-77, 1987

13. Del Bigio MR, Bruni JE: Changes in periventricular vasculature of rabbit brain following induction of hydrocephalus and after shunting. J Neurosurg 69:115-120, 1988

14. Del Bigio MR, Bruni JE, Vriend JP: Monoamine neurotransmitters and their metabolites in the mature rabbit brain following induction of hydrocephalus. Neurochem Res 23:1379-1386, 1998

15. Del Bigio MR, Vriend JP: Monoamine neurotransmitters and amino acids in the cerebrum and striatum of immature rats with kaolin-induced hydrocephalus. Brain Res 798:119-126, 1998

16. Del Bigio MR, Zhang YW: Cell death, axonal damage, and cell birth in the immature rat brain 
following induction of hydrocephalus. Exp Neurol 154:157-169, 1998

17. Ebisu T, Naruse S, Horikawa Y, et al: Discrimination between different types of white matter edema with diffusion-weighted MR imaging. J Magn Reson Imaging 3:863-868, 1993

18. Fatouros PP, Marmarou A: Use of magnetic resonance imaging for in vivo measurements of water content in human brain: method and normal values. J Neurosurg 90:109-115, 1999

19. Gideon P, Thomsen C, Gjerris F, et al: Increased self-diffusion of brain water in hydrocephalus measured by MR imaging. Acta Radiol 35:514-519, 1994

20. Hakim S, Venegas JG, Burton JD: The physics of the cranial cavity, hydrocephalus and normal pressure hydrocephalus: mechanical interpretation and mathematical model. Surg Neurol 5:187-210, 1976

21. Haraldseth O, Jones RA, Skottner A: A quantitative in-vivo MR imaging study of brain dehydration in diabetic rats and rats treated with peptide hormones. Magn Reson Imaging 15:203-210, 1997

22. Higashi K, Asahisa H, Ueda N, et al: Cerebral blood flow and metabolism in experimental hydrocephalus. Neurol Res 8:169-176, 1986

23. Hoehn-Berlage M, Eis M, Schmitz B: Regional and directional anisotropy of apparent diffusion coefficient in rat brain. NMR Biomed 12:45-50, 1999

24. James AE Jr, Strecker EP, Sperber E, et al: An alternative pathway of cerebrospinal fluid absorption in communicating hydrocephalus. Transependymal movement. Radiology 111:143-146, 1974

25. Jasinski A, Jakubowski T, Rydzy M, et al: Shielded gradient coils and radio frequency probes for high-resolution imaging of rat brains. Magn Reson Med 24:29-41, 1992

26. Jones HC, Andersohn RW: Progressive changes in cortical water and electrolyte content at three stages of rat infantile hydrocephalus and the effect of shunt treatment. Exp Neurol 154:126-136, 1998

27. Kaczmarek M, Subramanian RP, Neff SR: The hydromechanics of hydrocephalus: steady-state solutions for cylindrical geometry. Bull Math Biol 59:295-323, 1997

28. Kiricuta IC, Jr., Simplaceanu V: Tissue water content and nuclear magnetic resonance in normal and tumor tissues. Cancer Res 35:1164-1167, 1975

29. Kruger L, Saporta S, Swanson LW: Photographic Atlas of the Rat Brain. The Cell and Fiber Architecture Illustrated in Three Planes With stereotactic Coordinates. Cambridge, England: Cambridge University Press, 1995, p 299

30. Kuroiwa T, Nagaoka T, Ueki M, et al: Correlations between the apparent diffusion coefficient, water content, and ultrastructure after induction of vasogenic brain edema in cats. J Neurosurg 90:499-503, 1999

31. Lei H, Peeling J: A strategy to optimize the signal-to-noise ratio in one-coil arterial spin tagging perfusion imaging. Magn Reson Med 41:563-568, 1999

32. McAllister J II, Chovan P: Neonatal hydrocephalus. Mechanisms and consequences. Neurosurg Clin North Am 9:73-93, 1998 
33. McLone DG, Bondareff W, Raimondi AJ: Hydrocephalus-3, a murine mutant. II. Changes in the brain extracellular space. Surg Neurol 1:233-242, 1973

34. Nicholson C, Sykova E: Extracellular space structure revealed by diffusion analysis. Trends Neurosci 21:207-215, 1998

35. Pekar J, Jezzard P, Roberts DA, et al: Perfusion imaging with compensation for asymmetric magnetization transfer effects. Magn Reson Med 35:70-79, 1996

36. Penn RD, Bacus JW: The brain as a sponge: a computed tomographic look at Hakim's hypothesis. Neurosurgery 14:670-675, 1984

37. Strecker EP, James AE Jr, Kelley JE, et al: Semiquantitative studies of transependymal albumin movement in communicating hydrocephalus. Radiology 111:341-346, 1974

38. Szentistvanyi I, Patlak CS, Ellis RA, et al: Drainage of interstitial fluid from different regions of rat brain. Am J Physiol 246:F835-F844, 1984

39. Tamaki N, Yamashita H, Kimura M, et al: Changes in the components and content of biological water in the brain of experimental hydrocephalic rabbits. J Neurosurg 73:274-278, 1990

40. Thomas DL, Pell GS, Lythgoe MF, et al: A quantitative method for fast diffusion imaging using magnetization-prepared TurboFLASH. Magn Reson Med 39:950-960, 1998

41. Tsekos NV, Zhang F, Merkle H, et al: Quantitative measurements of cerebral blood flow in rats using the FAIR technique: correlation with previous iodoantipyrine autoradiographic studies. Magn Reson Med 39:564-573, 1998

42. Whittall KP, MacKay AL, Graeb DA, et al:In vivo measurement of T2 distributions and water contents in normal human brain. Magn Reson Med 37:34-43, 1997

43. Wise SP, Jones EG: The organization and postnatal development of the commissural projection of the rat somatic sensory cortex. J Comp Neurol 168:313-343, 1976

This work was supported in part by a grant from the Manitoba Health Research Council. Dr. Del Bigio is in receipt of a scholarship from the same agency.

Manuscript received August 30, 1999.

Accepted in final form September 2, 1999.

Address reprint requests to: Marc Del Bigio, M.D., Department of Pathology, University of Manitoba, D212-770 Bannatyne Avenue, Winnipeg, Manitoba R3E 0W3, Canada. 